Illa Arinta

\title{
FAKTOR- FAKTOR YANG MEMPENGARUHI PENGETAHUAN TENTANG BUKU KIA PADA IBU HAMIL
}

\author{
Illa Arinta \\ Akademi Kebidanan RSPAD Gatot Soebroto \\ Email : illa_arinta@akbidrspad.ac.id
}

\section{ABSTRACT FACTORS AFFECTING KNOWLEDGE ABOUT MCH BOOK ON PREGNANT MOTHERS}

Background. One of the major obstacles to the slow decline in MMR and IMR in Indonesia is the low maternal knowledge associated with pregnancy. Riskesdas 2012 research results nationally, mothers who own and bring books and understand the benefits only $29.1 \%$ and one of the provinces in Indonesia that is, East Java $42.1 \%$ of mothers who have books and $47.3 \%$ of mothers have but not Bring and $10.7 \%$ do not have (Ministry of Health RI, 2010).

The Purpose It is known the relationship between the characteristics of pregnant women and knowledge of the MCH book at the Cempaka Putih Sub-district Health Center and the Sawah Besar Public Health Center, Central Jakarta for the period February to August 2017

Research Method. The research design used was quantitative using cross sectional approach, the location of the research was conducted at Public Health Center and cempaka putih Public Health Center, with 214 samples of pregnant women. The instrument used is questionnaire. The variables used are education, occupation, parity and age.

Results. much as $80.0 \%$ of mother's knowledge is good, and only $19.2 \%$ are knowledgeable less. There is no significant correlation between education, occupation, age, parity with mother's knowledge about book in pregnant women at Cempaka Putih Public Health Center and Sawah Besar Public Health Center. There is a significant relation of mother job $(p=0,048), O R=4,596$, with knowledge of books on pregnant women at Cempaka Putih Public Health Center and Sawah Besar Public Health Center.

Conclusion. Knowledge of Pregnant Women About Book Cempaka Putih Public Health Center and Sawah Besar Public Health Center the most category that is less category.

Suggestion Maintain knowledge of pregnant women about the $\mathrm{MCH}$ handbook by evaluating pregnant women at every ANC examination so that mothers know more and actively understand about maternal and child health and mothers know better when to need help or an emergency.

Keywords : Knowledge, Pregnant, Maternal and Child Health Books

\section{ABSTRAK}

Latar Belakang. Salah satu kendala utama lambatnya penurunan AKI dan AKB di Indonesia adalah rendahnya pengetahuan ibu yang berhubungan dengan kehamilan. Hasil penelitian Riskesdas 2012 secara Nasional, ibu yang memiliki dan membawa buku KIA serta memahami manfaatnya hanya $29,1 \%$ dan salah satu propinsi di Indonesia yaitu, Jawa Timur 42,1\% ibu yang memiliki buku KIA dan 47,3\% ibu memiliki namun tidak membawa, dan 10,7\% tidak memiliki (Kemenkes RI, 2010). Hal ini menggambarkan masih banyak ibu hamil yang tidak mengetahui manfaat dan isi buku KIA.

Tujuan. Diketahuinya Faktor- Faktor Yang Mempengaruhi Pengetahuan Tentang Buku KIA Pada Ibu Hamil Di Puskesmas Kecamatan Cempaka Putih Dan Puskesmas Sawah Besar Jakarta Pusat Periode Februari s/d Agustus $2017 "$ ".

Metode. Desain penelitian yang digunakan adalah kuantitatif dengan menggunakan pendekatan cross sectional, lokasi penelitian dilaksanakan di Puskesmas Sawah Besar dan puskesmas cempaka putih Februari s/d Agustus 2017, dengan jumlah sampel 214 ibu hamil. Instrument yang digunakan adalah kuesioner. Variabel yang digunakan adalah pendidikan, pekerjaan, paritas, usia ibu.

Hasil. Sebanyak 80,0\% pengetahuan ibu adalah baik, dan hanya 19,2 \% yang berpengetahuan kurang. Tidak ada hubungan secara signifikan pendidikan, pekerjaan, usia, paritas dengan pengetahuan ibu tentang buku KIA pada ibu hamil di Puskesmas Kecamatan Cempaka Putih dan Puskesmas Sawah Besar Tahun 2017. Ada hubungan secara signifikan pekerjaan ibu $(p=0,048), O R=4,596$, dengan pengetahuan tentang buku KIA pada ibu hamil di Puskesmas Kecamatan Cempaka Putih dan Puskesmas Sawah Besar. 


\section{JKM (Jurnal Kebidanan Malahayati),Vol 7,No.4.Oktober 2021, \\ ISSN (Print) 2476-8944 ISSN (Online) 2579-762X, Hal 658-663}

Kesimpulan Tidak ada hubungan signifikan pendidikan, pekerjaan, usia, paritas dengan pengetahuan ibu tentang buku KIA, ada hubungan signifikan pekerjaan ibu dengan pengetahuan tentang buku KIA.

Saran Mempertahankan pengetahuan ibu hamil tentang buku KIA dengan mengevaluasi ibu hamil pada setiap pemeriksaan ANC agar ibu lebih mengetahui dan memahami secara aktif tentang kesehatan ibu dan anak serta ibu lebih mengetahui kapan memerlukan pertolongan atau kegawatdaruratan.

Kata kunci : Pengetahuan, Ibu hamil, Buku kesehatan ibu dan anak (KIA)

\section{PENDAHULUAN}

Buku Kesehatan Ibu dan Anak (KIA) merupakan buku pedoman yang dimiliki oleh ibu dan anak, yang berisi informasi dan catatan kesehatan ibu dan anak serta merupakan satusatunya alat pencatatan pelayanan kesehatan ibu dan anak sejak ibu hamil, melahirkan dan selama masa nifas hingga bayi yang dilahirkan berusia 5 tahun (Kemenkes RI, 2004).

Kebijakan dan berbagai upaya pemerintah untuk menurunkan angka kematian ibu dan bayi, antara lain dengan kegiatan Gerakan Sayang Ibu (GSI), Strategi Making Pregnancy Safer dan pengadaan buku Kesehatan Ibu dan Anak (KIA). Buku KIA telah diperkenalkan sejak tahun 1990 dengan bantuan Badan Kerjasama Internasional Jepang (JICA). Dikeluarkannya Buku KIA ini diarahkan untuk meningkatkan pengetahuan dan pemahaman masyarakat tentang kesehatan ibu dan anak (Kemenkes RI, 2004).

Berdasarkan hasil survey penelitian yang dilakukan pada tanggal 23 Maret 2017 didapatkan jumlah ibu hamil di Puskesmas Kecamatan Cempaka Putih sebanyak 12 ibu hamil, penyebaran buku KIA disekitar wilayah kerja Puskesmas Kecamatan Cempaka Putih sudah merata penyebarannya, tetapi dalam penggunaanya masih belum semua ibu hamil yang mempunyai buku KIA paham mengenai isi dari buku KIA. Setelah dilakukan wawancara dengan pertanyaan buku KIA kepada 8 ibu hamil yang melakukan ANC ada 2 ibu hamil bisa menjawab pertanyaan tentang buku KIA dan 6 ibu hamil tidak bisa menjawab tentang buku KIA. Sedangkan berdasarkan hasil survey pendahuluan tanggal 17 Maret didapatkan jumlah ibu hamil di Puskesmas Kecamatan Sawah Besar sebanyak 15 ibu hamil setelah dilakukan wawancara kepada ibu hamil yang melakukan ANC ada 6 ibu hamil yang mengetahui tentang isi buku $\mathrm{KIA}$ dan ada 9 ibu hamil yang kurang mengetahui tentang buku KIA. Dari hasil wawancara tersebut menunjukkan bahwa lebih banyak ibu hamil yang belum mengetahui buku KIA.

\section{METODE PENELITIAN}

Desain penelitian yang digunakan adalah kuantitatif dengan meggunakan pendekatan cross sectional, yaitu penelitian yang mempelajari dinamika korelasi antara faktor-faktor resiko dengan efek melalui cara pendekatan, observasi atau pengumpulan data sekaligus ( point time approach ), yang artinya suatu kedaan yang dinilai pada waktu yang sama. Dan penelitian ini menggunakan data primer yaitu data yang langsung diambil dari subyek penelitian.

Dalam penelitian ini peneliti ingin mengetahui Faktor- Faktor Yang Mempengaruhi Pengetahuan Tentang Buku KIA Pada Ibu Hamil.

Lokasi penelitian adalah di Puskesmas Kecamatan Cempaka Putih dan Puskesmas Sawah Besar. Waktu pelaksanaan Februari s/d Agustus Tahun 2017.

\section{HASIL PENELITIAN \\ Pengetahuan}

Tabel 1.

Distribusi Frekuensi pengetahuan tentang buki KIA

\begin{tabular}{lcc}
\hline Pengetahuan & Frekuensi & Persentase \% \\
\hline Baik & 173 & 80,8 \\
Kurang & 41 & 19,2 \\
\hline \multicolumn{1}{c}{ Jumlah } & 241 & 100 \\
\hline
\end{tabular}

Hasil penelitian didapatkan bahwa 214 ibu hamil sebagian besar memiliki pengetahuan baik sejumlah $173(80,8 \%)$, dengan pengetahuan kurang sebesar 41 orang $(19,2 \%)$.

\section{Pendidikan}

Tabel 2.

Distribusi Frekuensi pendidikan

\begin{tabular}{lcc}
\hline Pendidikan & Frekuensi & Persentase $\%$ \\
\hline Tinggi & 154 & 71,9 \\
Rendah & 60 & 28,1 \\
\hline Jumlah & 214 & 100 \\
\hline
\end{tabular}


Berdasarkan tabel diatas bahwa sebagian besar berpendidikan tinggi sejumlah $154(71,9 \%)$, dan berpendidikan rendah yaitu $60(28,1 \%)$.

\section{Pekerjaan}

Tabel 3.

Distribusi Frekuensi pekerjaan

\begin{tabular}{lcc}
\hline \multicolumn{1}{c}{ Pekerjaan } & Frekuensi & Persentase $\%$ \\
\hline bekerja & 35 & 16,4 \\
Tidak bekerja & 179 & 83,4 \\
\hline \multicolumn{1}{c}{ Jumlah } & 214 & 100 \\
\hline
\end{tabular}

Hasil penelitian didapatkan lebih banyak ibu yang tidak bekerja yaitu 179 (83,6\%), dibandingkan ibu bekerja yaitu 35 orang $(16,4 \%)$

\section{Paritas}

Tabel 4.

Distribusi Frekuensi paritas

\begin{tabular}{ccc}
\hline Paritas & Frekuensi & Persentase $\%$ \\
\hline primipara & 78 & 36,4 \\
mutipara & 136 & 63,6 \\
\hline Jumlah & 214 & 100 \\
\hline
\end{tabular}

Hasil penelitian bahwa dari 214 ibu hamil sebagian besar ibu multipara sebanyak 136(63\%), sedangkan primipara sebanyak $78(36,45)$.

Usia

Tabel 5

Distribusi Frekuensi Usia

\begin{tabular}{ccc}
\hline Usia & Frekuensi & Persentase $\%$ \\
\hline Resiko & 31 & 14,5 \\
Tidak beresiko & 183 & 85,5 \\
\hline Jumlah & 49 & 100 \\
\hline
\end{tabular}

Berdasarkan tabel disimpulkan bahwa dari 214 hamil sebagian besar berusia tidak beresiko yaitu $183(85,5 \%)$, dan usia beresiko yaitu 31 $(14,55)$.

\section{Analisa Bivariat}

Pengetahuan Ibu Hamil Tentang Buku KIA dengan pendidikan tinggi adalah berpengetahuan baik $96(81,4 \%)$ dan pendidikan tinggi dengan pengetahuan kurang $22(18,6 \%)$. Ibu dengan pendidikan rendah dengan pengetahuan baik 77 ( $80,2 \%$ ) dan lbu dengan pendidikan Rendah dengan pengetahuan kurang $19(19,8 \%)$. Tidak ada hubungan yang bermakna antara pengetahuan dengan pendidikan.

Tabel 6.

Hubungan pengetahuan dengan pendidikan

\begin{tabular}{lcccc}
\hline \multirow{2}{*}{ Pendidikan } & \multicolumn{2}{c}{ Pengetahuan } & \multirow{2}{*}{ Total (100\%) } & \multirow{2}{*}{ P value } \\
\cline { 2 - 3 } & Baik (\%) & Kurang (\%) & & \\
\hline Tinggi & $96(81,4 \%)$ & $22(18,6 \%)$ & $118(55,1 \%)$ & \multirow{2}{*}{0,970} \\
Rendah & $77(80,2 \%)$ & $19(19,8 \%)$ & $96(44,9 \%)$ & \\
\hline \multicolumn{1}{c}{ Total } & 173 & 41 & 214 & \\
\hline
\end{tabular}

Tabel 7.

Hubungan pengetahuan Dengan pekerjaan

\begin{tabular}{lcccc}
\hline \multirow{2}{*}{ Pekerjaan } & \multicolumn{2}{c}{ Pengetahuan } & \multirow{2}{*}{ Total $(\mathbf{1 0 0 \% )}$} & \multirow{2}{*}{ P value } \\
\cline { 2 - 3 } & Baik (\%) & Kurang (\%) & & \\
\hline Bekerja & $33(94,3 \%)$ & $2(5,7 \%)$ & $35(16,3 \%)$ & \multirow{2}{*}{0,048} \\
Tidak bekerja & $140(78,2 \%)$ & $39(21,8 \%)$ & $179(83,7 \%)$ & \\
\hline \multicolumn{1}{c}{ Total } & 173 & 41 & 214 & \\
\hline
\end{tabular}

Hasil penelitian pengetahuan tentang buku $\mathrm{KIA}$ yaitu berpengetahuan baik dengan ibu bekerja sebesar $94,3 \%$. Ada hubungan yang bermakna antara pengetahuan dengan pekerjaan. 
Tabel 8.

Hubungan pengetahuan dengan usia

\begin{tabular}{ccccc}
\hline \multirow{2}{*}{ Usia } & \multicolumn{2}{c}{ Pengetahuan } & \multirow{2}{*}{ Total (100\%) } & \multirow{2}{*}{ P value } \\
\cline { 2 - 3 } & Baik (\%) & Kurang (\%) & & \\
\hline Tidak beresiko & $148(82,1 \%)$ & $35(17,6 \%)$ & $183(85,5 \%)$ & \multirow{2}{*}{0,985} \\
beresiko & $25(25 \%)$ & $6(38,1 \%)$ & $31(14,5 \%)$ & \\
\hline Total & 173 & 41 & 214 & \\
\hline
\end{tabular}

Hasil penelitian yaitu Pengetahuan Tentang Buku KIA pada usia tidak beresiko dengan berpengetahuan baik $148(82,1 \%)$ dan usia tidak beresiko dengan berpengetahuan kurang 35 ( 17,6 $\%$ ). Pada usia beresiko dengan pengetahuan baik
25 ( 61,9 \% ) dan usia beresiko dengan pengetahuan kurang $6(38,1 \%)$. Tidak ada hubungan yang bermakna antara pengetahuan dengan usia.

Tabel 9.

Hubungan pengetahuan dengan paritas

\begin{tabular}{ccccc}
\hline \multirow{2}{*}{ Paritas } & \multicolumn{2}{c}{ Pengetahuan } & \multirow{2}{*}{ Total (100\%) } & \multirow{2}{*}{ P value } \\
\cline { 2 - 3 } & Baik (\%) & Kurang (\%) & & \\
\hline Primigravida & $63(82,1 \%)$ & $15(17,6 \%)$ & $78(36,4 \%)$ & \multirow{2}{*}{0,993} \\
Multigravida & $110(61,9 \%)$ & $26(38,1 \%)$ & $136(62,7 \%)$ & \\
\hline Total & 173 & 41 & 214 & \\
\hline
\end{tabular}

Pengetahuan Ibu Hamil pada primigravida adalah berpengetahuan baik 63 ( $82,1 \%)$ dan primigravida dengan pengetahuan kurang 15 ( 17,6 $\%$ ). Pada Multigravida dengan pengetahuan baik 110 ( $61,9 \%$ ) dan multigravida dengan pengetahuan kurang $26(38,1 \%)$.

\section{PEMBAHASAN}

\section{Pengetahuan}

Hasil penelitian di Puskesmas Kecamatan Cempaka Putih menunjukkan dari 214 ibu hamil $173(80,8 \%)$ diantaranya berpengetahuan baik. Hasil penelitian ini sesuai dengan teori Notoatmodjo 2012 yang berpendapat bahwa Pengetahuan adalah hasil penginderaan manusia, atau hasil tahu seseorang terhadap objek melalui indera yang dimilikinya (mata, hidung, telinga, dan sebagainya). Pada waktu pengindraan sampai hasil pengetahuan tersebut sangat di pengaruhi oleh intensitas perhatian dan persepsi terhadap obyek. Demikian juga Dewey (2010) mengatakan bahwa pengetahuan adalah perkembangan pandangan instrumentalis pragmatis, dimana kecerdasan dilihat sebagai penyesuaian yang sensitif dan fleksibel. Pengetahuan seseorang biasanya diperoleh dari pengalaman yang berasal dari berbagai macam sumber, misalnya media massa, media elektronik, buku petunjuk, petugas kesehatan, media poster, kerabat dekat dan sebagainya. Sesuai juga dengan penelitian Kismoyo 2005 yang menyebutkan pengetahuan ini dapat membantu keyakinan tertentu sehingga seseorang berperilaku sesuai keyakinan tersebut. Sejalan dengan teori Nursalam (2009) yang menyatakan bahwa semakin tinggi tingkat pendidikan seseorang, maka makin mudah menerima informasi sehingga makin banyak pula pengetahuan yang dimiliki.

\section{Hubungan pengetahuan dengan pendidikan}

Hasil penelitian menunjukkan pendidikan dengan pengetahuan baik $96(81,4 \%)$. uji statistik menunjukkan bahwa tidak terdapat hubungan antara pendidikan ibu dengan pengetahuan tentang buku KIA. Berdasarkan teori Yunus (2009) yang menyatakan bahwa pendidikan adalah suatu usaha yang dengan sengaja dipilih untuk mempengaruhi dan membantu anak yang bertujuan untuk meningkatkan ilmu pengetahuan, jasmani dan akhlak sehingga secara perlahan bisa mengantarkan anak kepada tujuan dan cita-citanya yang paling tinggi. Demikian halnya menurut Notoatmodjo 2012 yang menyatakan Pendidikan adalah salah satu usaha untuk mengembangkan kepribadian dan kemampuan berlangsung seumur hidup. Sesuai juga dengan Nursalam 2008 yang mengatakan bahwa tingkat pendidikan yang kurang akan menghambat perkembangan dan sikap seseorang terhadap nilai-nilai yang baru diperkenalkan. 
Demikian juga sesuai yang dikemukakan KBBI Pendidikan yaitu sebuah proses pembelajaran bagi setiap individu untuk mencapai pengetahuan dan pemahaman yang lebih tinggi mengenai obyek tertentu dan spesifik. Pengetahuan yang diperoleh secara formal tersebut berakibat pada setiap individu yaitu memiliki pola pikir, perilaku dan akhlak yang sesuai dengan pendidikan yang diperolehnya. Dan sejalan dengan teori Hidayat 2009 Pendidikan ibu mempunyai pengaruh dalam pengetahuan ibu hamil terhadap isi buku KIA, karena dengan pendidikan yang tinggi dianggap seseorang akan memiliki pengetahuan yang tinggi pula. menurut Nursalam (2009) yang menyatakan bahwa semakin tinggi tingkat pendidikan seseorang, maka makin mudah menerima informasi sehingga makin banyak pula pengetahuan yang dimiliki. Sebaliknya pendidikan yang kurang akan menghambat pengetahuan dan perkembangan sikap seseorang terhadap nilai-nilai yang baru diperkenalkan.

\section{Hubungan pengetahuan dengan pekerjaan}

Hasil penelitian menunjukkan pekerjaan dengan pengetahuan baik $33(94,3 \%)$. uji statistik menunjukkan bahwa terdapat hubungan antara pekerjaan ibu dengan pengetahuan buku KIA. Hal ini sejalan dengan teori Hidayat 2009 yang menyatakan bahwa ibu yang bekerja adalah ibu-ibu yang melakukan aktifitas ekonomi mencari penghasilan baik disektor formal maupun informal, yang dilakukan secara regular di luar rumah. Tentunya aktifitas ibu yang bekerja akan berpengaruh terhadap waktu yang dimiliki ibu untuk membaca buku KIA. Meskipun tanpa dasar pengetahuan yang memadai ternyata di kalangan ibu tidak bekerja pengetahuan mereka tentang buku KIA lebih baik dibanding ibu yang bekerja.

Demikian halnya menurut Nursalam 2008 ibu yang tidak bekerja dapat saling berpengaruh karena melihat waktu yang dimiliki oleh seorang ibu rumah tangga lebih banyak dirumah sehingga dimungkinkan hubungan komunikasi dengan lingkungannya akan lebih erat dibandingkan ibu rumah tangga yang bekerja, yang mana hal tersebut dapat berpangaruh pada pola pikir dan perilaku karena dari lingkungan dapat lahir informasi, pengetahuan, kebudayaan, pengalaman, pendapatan dan kepercayaan seseorang, untuk itu keadaan lingkungan sangat berpengaruh dalam pembentukan suatu tatanan individu dan masyarakat. Yang mana hal tersebut pada akhirnya akan mempengaruhi tingkat pengetahuan dan bentuk perilaku.

Sejalan dengan teori Gulo W (2004) Ibu yang bekerja adalah ibu-ibu yang melakukan aktifitas ekonomi mencari penghasilan baik disektor formal maupun informal, yang dilakukan secara reguler diluar rumah. Tentunya ibu yang bekerja, aktifitas ibu yang bekerja akan berpengaruh terhadap waktu yang dimiliki ibu untuk membaca buku KIA. Meskipun tanpa sadar pengetahuan yang memadai ternyata dikalangan ibu tidak bekerja pengetahuan mereka tentang buku KIA lebih baik dibanding ibu yang bekerja (Hidayat, 2009).

\section{Hubungan pengetahuan dengan usia}

Hasil penelitian menunjukkan usia dengan pengetahuan baik 148 (82,1\%). uji statistik menunjukkan bahwa tidak terdapat hubungan antara usia ibu dengan pengetahuan buku KIA. Hal ini sesuai dengan teori Hidayat 2009 bahwa pada usia kurang dari 20 tahun, seorang wanita baru beranjak dari fase remaja menuju fase dewasa sehingga pada usia tersebut emosi seseorang masih belum stabil dan lebih banyak memikirkan dirinya sendiri daripada memikirkan keluarganya dan pada usia tersebut pada seorang wanita belum adanya kesadaran dalam pentingnya kesehatan sehingga sedikit yang membaca buku KIA. Usia antara 20-35 tahun adalah usia dimana seseorang sudah matang dan berfikir lebih dewasa sehingga pengetahuannya lebih baik. Dan pada umur diatas 35 tahun biasanya seorang wanta mulai khawatir dan sudah berfikir bahwa dirinya mulai beranjak ke usia yang lebih tua sehingga pikiran mereka terbagi antara dirinya sendiri dan perhatian terhadap anakanaknya. Maka dari itu di usia ini ibu lebih baik lagi pengetahuannya karena di tambah pengalaman pula.

Sesuai juga dengan Nuswantari 2013 Usia dengan lamanya keberadaan seseorang diukur dalam satuan waktu dipandang dari segi kronologik, individu normal yang memperlihatkan derajat perkembangan anatomis dan fisiologik sama. Demikian halnya Hoetomo 2012 Usia adalah lama waktu hidup atau ada sejak dilahirkan atau diadakan. Sehingga tidak ada kesenjangan antara teori dengan kenyataan hal ini sesuai dengan teori Notoadmojo (2010) yang menyatakan bahwa pada ibu yang berusia 20 - 35 tahun biasanya berfikir lebih dewasa sehingga pengetahuannya lebih baik. Pada usia kurang dari 20 tahun, seorang wanita baru beranjak dari fase remaja menuju ke fase dewasa sehingga pada usia tersebut emosi seseorang masih belum stabil dan lebih banyak memikirkan dirinya sendiri dari pada memikirkan keluarganya dan pada usia tersebut pula seorang wanita belum adanya kesadaran dalam pentingnya kesehatan sehingga sedikit yang membaca buku KIA. Usia antara 20-35 tahun adalah usia dimana 


\section{JKM (Jurnal Kebidanan Malahayati),Vol 7,No.4.Oktober 2021, \\ ISSN (Print) 2476-8944 ISSN (Online) 2579-762X, Hal 658-663}

seseorang udah matang dan berfikir lebih dewasa sehingga pengetahuannya lebih baik. Dan pada umur diatas 35 tahun biasanya seorang wanita mulai khawatir dan sudah berfikir bahwa dirinya mulai beranjak ke usia yang lebih tua sehingga pikiran mereka terbagi antara dirinya sendiri dan perhatian terhadap anak-anaknya. (Hidayat 2009).

\section{Hubungan pengetahuan dengan paritas}

Hasil penelitian menunjukkan paritas primigravida dengan pengetahuan baik 63 (82,1\%). uji statistik menunjukkan bahwa tidak terdapat hubungan antara paritas ibu dengan pengetahuan buku KIA. Hasil penelitian ini sesuai dengan teori Suhartono 2005 yang mengemukakan pengalaman melahirkan anak adalah sesuatu yang dirasakan yang juga merupakan kesadaran dan tertangkap oleh indra manusia sehingga akan melekat di ingatan seorang ibu yang pernah melahirkan. lbu yang hamil akan mendapatkan buku KIA dan akan menggunakanya sampai anaknya berusia 5 tahun. Ibu yang sudah pernah melahirkan dan mendapat buku KIA pada anak pertama sudah sepantasnya mengetahui tentang buku KIA saat mempunyai anak kedua karena sudah mempunyai pengalaman menggunakan buku tersebut pada anak pertama. Hal ini juga sejalan dengan hasil penelitian Silvia yang menyebutkan ibu primipara cenderung belum banyak mengetahui tentang informasi- informasi apa saja yang terdapat di dalam Buku Kesehatan lbu dan Anak (KIA).

Hal ini sesuai teori Karsnodiharjo (2006) yang mengatakan paritas dapat mempengaruhi pengetahuan seseorang dimana pengetahuan seseorang diperoleh dari pengalaman sendiri maupun pengalaman orang lain. Misalnya sebagian ibu hamil yang memiliki anak lebih dari satu sudah mengetahui isi dari buku KIA. Seorang ibu yang pernah melahirkan setidaknya telah mengerti mengenai kehamilan, persalinan, nifas, imunisasi, sehingga ibu diharapkan lebih banyak pengetahuannya tentang buku KIA. Bobak (2006) menyatakan seseorang ibu yang memiliki anak lebih dari satu sudah mempunyai pengalaman untuk membaca buku KIA.

\section{SIMPULAN}

Sejumlah 80,0 \% pengetahuan ibu adalah baik, dan hanya 19,2\% yang berpengetahuan kurang. Tidak ada hubungan secara signifikan pendidikan, pekerjaan, usia, paritas dengan pengetahuan ibu tentang buku KIA. Ada hubungan secara signifikan pekerjaan ibu $(p=0,048)$, $\mathrm{OR}=4,596$, dengan pengetahuan tentang buku KIA.

\section{SARAN}

Mempertahankan pengetahuan ibu hamil tentang buku KIA dengan mengevaluasi ibu hamil pada setiap pemeriksaan ANC agar ibu lebih mengetahui dan memahami secara aktif tentang kesehatan ibu dan anak serta ibu lebih mengetahui kapan memerlukan pertolongan atau kegawatdaruratan.

\section{DAFTAR PUSTAKA}

Arikunto, S. 2010. Prosedur Penelitian: Suatu pendekatan Praktik. Jakarta: Rineka Cipta.

Depkes RI. 2009. Buku Kesehatan Ibu dan Anak (KIA). Jakarta: Depkes dan JICA.

Depkes RI. 2000. Kanwil Kesehatan Provinsi Sulawesi Utara Tahun 2000. Sulawesi Utara: Dinas Kesehatan Sulawesi Utara.

Depkes RI. 2001. Petunjuk Teknis Penggunaan Buku Kesehatan Ibu dan Anak. Jakarta: Depkes dan JICA.

Hidayat Aziz Alimul. 2014. Metode Penelitian Kebidanan dan Teknik Analisi Data. Edisi 2. Jakarta: Salemba Medika.

Kismoyo, C. 2005. Hubungan Tingkat Pengetahuan Ibu Hamil Tentang Gizi dan Anemia dengan Kadar Hemoglobin di Puskesmas Banguntapan. KTI. Fakultas Kedokteran Universitas Gadjah Mada. Yogyakarta.

Manuaba. 2012. IImu Kebidanan. Edisi 2. Jakarta: EGC.

Notoatmodjo, S. 2011. Kesehatan Masyarakat IImu dan Seni. Jakarta : Rineka Cipta.

Silvia S. Setyaningrum. Gambaran tingkat pengetahuan, sikap dan praktik ibu hamil terhadap penggunaan buku kia sebagai sumber referensi di desa leyangan ungaran. Skripsi

Tim Penyusun Kamus Pusat. 2002. KBBI (Kamus Besar Bahasa Indonesia). Jakarta: Balai Pustaka. 